\title{
Hippocrates and Ms. Payne
}

$\mathrm{M}$ s. Dolores Payne first came to see me last year seeking a second opinion for her abdominal pain. Under the care of another gastroenterologist, her symptoms hadn't improved and the usual battery of tests had been negative. She described excruciating lower abdominal pain radiating around to her back accompanied by alternating diarrhea and constipation. When the pain was at its worst, she had uncontrolled vomiting as well. I came to the conclusion that Ms. Payne was suffering from irritable bowel syndrome. A clue to our poor understanding of the condition is attested to by the word "irritable." There are no diseases such as grouchy heart, irascible lung, petulant pancreas or cantankerous kidney. Only the gut has a mood disorder. I made some dietary modifications and started her on belladonna. I told her that her condition was not serious and she should expect resolution of her problem over the next few months. She seemed very appreciative of my opinion and promised to follow the regimen. I fully anticipated that she would return in three weeks feeling much improved. I could not have been more misguided.

One night I received a call from the emergency room physician. Ms. Payne had returned with a similar constellation of complaints. When I saw her the next morning, she had the same lugubrious facies and her lower abdomen was tender to palpation. No, my treatment had not worked and if anything she felt worse. Her hospitalist thought that the correct diagnosis could have been missed on her previous admission and ordered a new series of tests, which of course came back negative. Her symptoms became more tolerable, I stopped the intravenous morphine, and she was discharged. Ten days later, she was back in the emer-

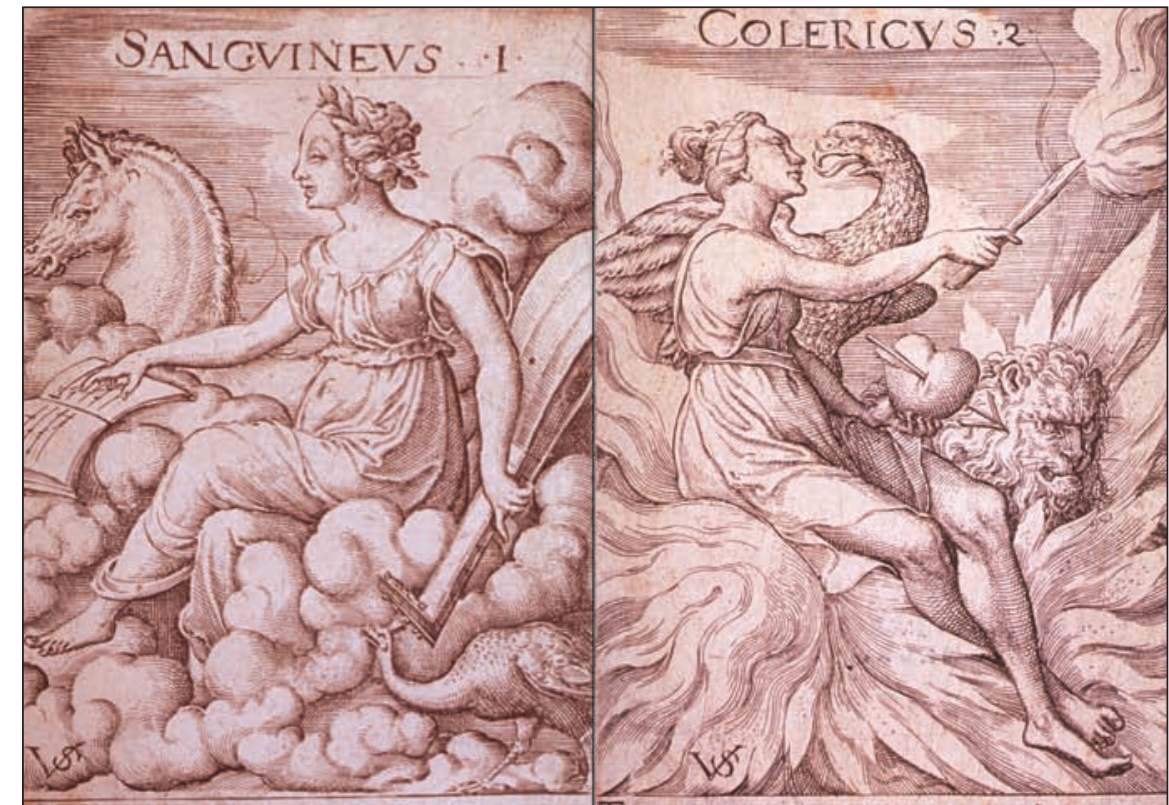

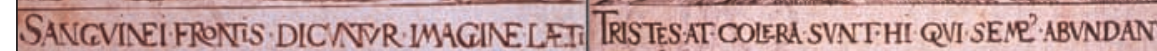
VNDEVOLVNT HILRES SEPE VIDERE IOC' FOREEREFFCTV OVE MOVET TONME SVO -

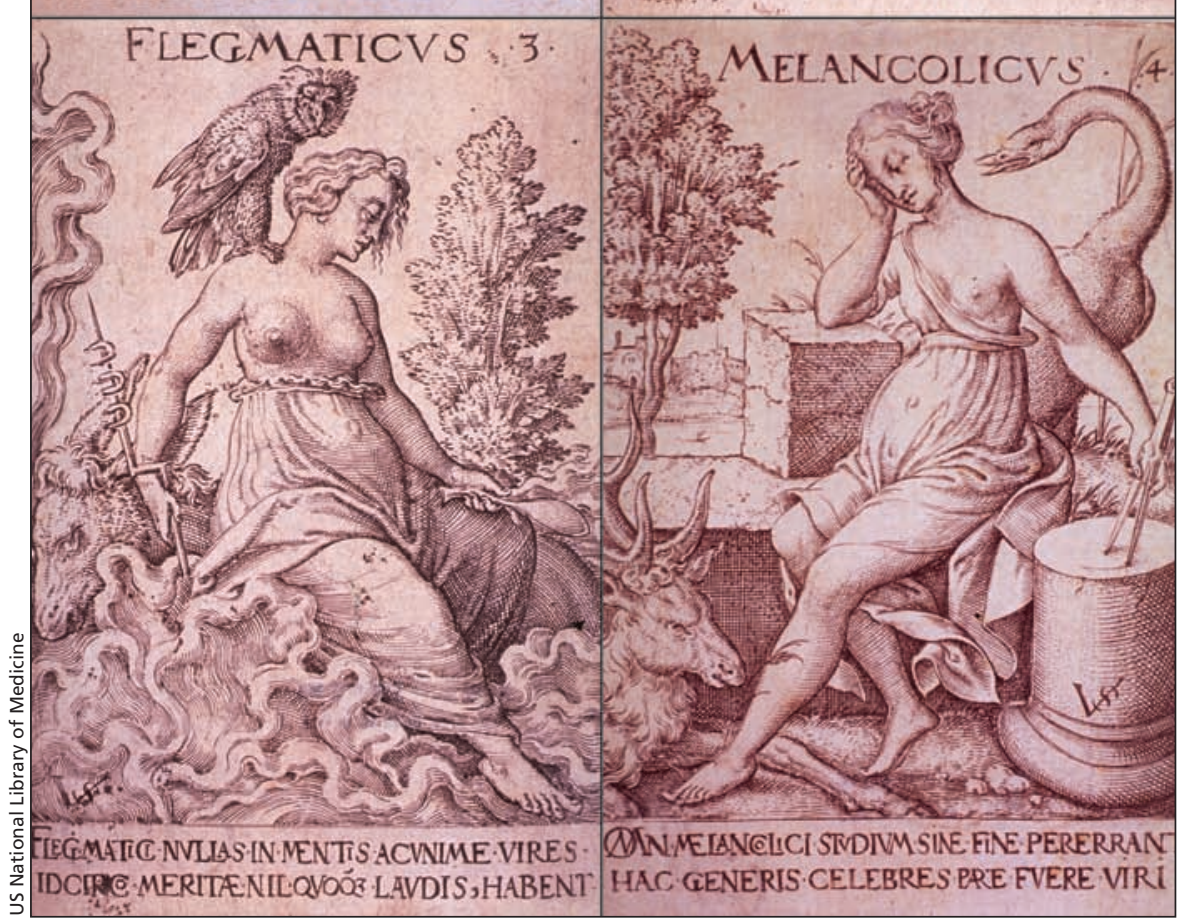

The four humors of Hippocratic medicine are, clockwise from the upper left, blood (L. sanguis), yellow bile (Gk. chole), phlegm (Gk. phlegma) and black bile (Gk. melan chole). Each corresponds to one of the traditional four temperaments. 
gency room. I consulted a surgical colleague who agreed that this was not an operable condition. A psychiatrist saw her and suggested an antidepressant. I changed her medications.

She returned to the office three weeks later. When I saw her name on the examining room door, an anxious feeling came over me. What if Ms. Payne was no better? I gently opened the door and tiptoed into the room. Her face was contorted with anguish and agony and I knew that I had failed. Over the course of the next few months, I tried every treatment in my armamentarium. I prescribed all the antis: antispasmodics, antacids, antibiotics and antiemetics (I would have tried antipasto if I thought it could work). I then switched to the pros: probiotics, promotility agents and Protonix. Nothing helped. Finally, one day in the office, I confessed to her that my treatment had been completely unsuccessful. I suggested that she seek another opinion, although in our state, not many specialists would take her Medicaid insurance and there was a six-month wait to see a university consultant. Ms. Payne seemed dismayed by

\section{Finally, one day in the office, I confessed to her that my treatment had been completely unsuccessful.}

my admission of failure and replied that I was a good doctor who was giving my best effort and she still wanted to be my patient. Even though this kind of gratitude is what doctors thrive on, my inner voice was howling: No! No! No!

I arrived home that night in a despondent mood thinking about the bleak prospect of treating Ms. Payne for the remainder of my medical career. I nagged at my wife and barked at the dog. I turned on the TV and started mindlessly flipping the channels. I flossed my teeth and stumbled into bed expecting a restless night with visions of Dolores Payne interrupting my sleep.

Suddenly I was in ancient Greece and to my astonishment, I was in a group of acolytes listening to a lecture from Hippocrates himself. He looked at me and asked "Who are you?" and I replied, "Margolis, sir, from the 21st century." "Oh, is that a Greek name?" he asked. "No, sir, Jewish." "Well what do you want Margolis?" "I came to ask you about my patient Dolores Payne who I can't get well." I proceeded to present her story. As I was talking, Hippocrates had a pensive look and after I had finished, he began to speak. "I commend you for your detailed history but I don't understand all of the silly tests that you performed; totally unnecessary. It's clear that she has imbalance of the four humors." "The four humors?" I asked. "Yes, the human body consists of four substances; blood, yellow bile, black bile and phlegm. Don't they teach that anymore? Your patient has too much black bile coming from the spleen and that's causing her melancholy and bad temper. I suggest an herbal regimen of white hellebore, thapsian and cucumber juice to restore that balance. If that fails some daucke or cuckoo-pint might help." I awoke startled, and looked at the clock, it was 2 am. moist clay, spices and herbs and I would apply the leeches daily." I slumbered on and soon I was in Philadelphia in the 18th century and I was discussing Ms. Payne with Dr. Benjamin Rush, the famous physician who signed the Declaration of Independence. After hearing my story, he told me that the cure was obvious." Bleed her until she faints and then purge her with large doses of calomel (mercurous chloride)."

The next thing I knew, it was morning. I mulled over my dreams and was thankful to be alive in the current century. The ancients were clueless in their treatments. I got dressed and drove to work, but I couldn't stop thinking of Hippocrates. When I arrived at my office, I opened the bottom drawer of my desk and found an old copy of the Hippocratic Oath that I had kept since medical school. I started to read. My eyes drifted down to the fourth line, "I will remember that there is art to medicine as well as science, and that warmth, sympathy, and understanding may outweigh the surgeon's knife or the chemist's drug." I immediately realized that this was a role that physicians have played since the beginning of civilization. Even in our technologic age, we don't have all the answers. Maybe, 50 or a 100 years from now, my antis and pros will be as laughable as cuckoo-pint or theriac tonic; but we will still sit in the examining room, put down our computers, listen to our patients and try to give them comfort. I recently saw Ms. Payne in the office. As far as I could tell, she hadn't improved but we talked about our children and grandchildren and our hopes for their future, and she seemed less anxious and a little more optimistic when the visit ended. She went to the check-out desk and made another appointment. She will be coming back in three weeks.

\section{David Margolis MD \\ Gastroenterologist}

St. Louis, Mo.

pulse and of course that's made in the liver. There's no doubt that she has more dark blood than red blood and because she is a Virgo, I suggest some theriac tonic consisting of ground-up lizard and viper flesh along with some
The author confirms that all the characters in this work are fictitious.

CMAJ 2012. DOI:10.1503/cmaj.111773 